\title{
Baniten
}

\section{Sick at heart}

ABORIGINAL Australians have a greater burden of illness and die younger than other Australians, according to a government study. The health disadvantage of

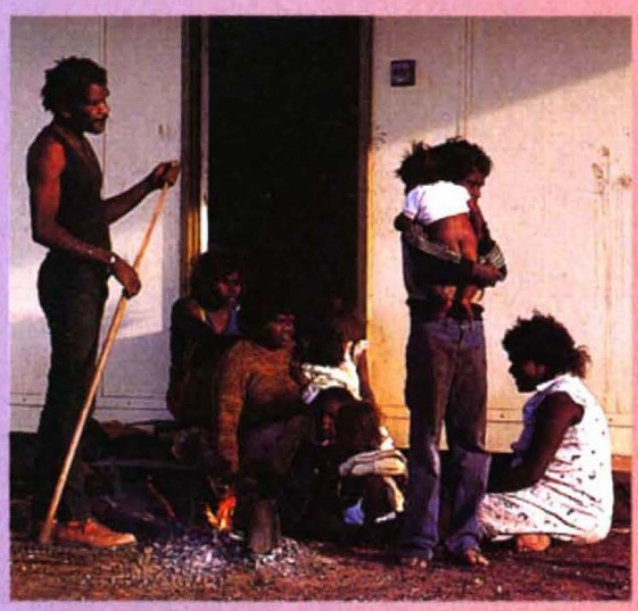
Aborigines begins early in life. Indigenous women bear children at a younger age, and their offspring are between two and three times more likely to suffer from low birthweight or to die at birth, than other Australians. Between 1992 and 1994, the life expectancy of Aborigines was between 15 and 20 years shorter than for non-indigenous Australians. The death rate was higher at all ages, but up to eight times higher among adults aged 25 to 54 .

Poor housing, high rates of infectious disease in children, poor diet, and low self-esteem that encourages heavy smoking and alcohol abuse, are all blamed for the the Aborigines ill health. Alcohol abuse in turn leads to a high rate of violence and injury.

Keith Woollard, president of the Australian Medical Association, said that the Aborigines' poor health could be blamed in part on their historical bad treatment, particularly dispossession from their land, which had contributed to a decline in their self-esteem.

The report, The Health and Welfare of Australia's Aboriginal and Torres Strait Islander Peoples, 1997, was produced jointly by the Australian Bureau of Statistics, the government's main statistical watchdog, and the Australian Institute of Health and Welfare.

ELIZABETH BAN Sydney

\section{Strict rules "could make transplants unworkable"}

Decades after Japan's first and only heart transplant ended in controversy, the lower house of Japan's parliament has passed an organ transplant bill which for the first time recognizes the concept of "brain death" as death and sets out clear criteria for harvesting hearts and livers. But the bill, which has yet to be passed by the upper house of the parliament, includes extremely strict donation rules which will make it very difficult for surgeons to perform transplants.

Relatives will not have the right to give permission for hearts and livers to be harvested following brain death without prior written permission from the donor. Ironically, they will have the right to withhold permission even if this written permission exists.

Surgeons fear that it may become legal but practically impossible to perform heart and liver transplants because very few organs will become available. Japanese people are extremely reluctant to donate organs and it is rare for people to carry donor cards. Transplants of kidneys and corneas, which are already legal because they can be harvested from donors whose hearts have stopped beating, are uncommon in Japan despite more relaxed donation rules in which the relatives' permission alone is sufficient.

RICHARD NATHAN Tokyo

\section{Tuskegee apology}

U.S. President Bill Clinton has offered a formal apology to the families and survivors of a group of almost 400 black men who were denied treatment for syphilis in experiments conducted by the Public Health Service in Tuskegee, Alabama, earlier this century. During the course of the experiments to study how syphilis spreads and how it kills, the government withheld therapies of known, if imperfect, value from almost 400 black men. The study, started in 1932, did not end until 1972, even after penicillin supplanted mercury and other treatments for the disease.

B.J.C.

\section{Jail ends Gajdusek saga}

Nobel laureate D. Carleton Gajdusek, who established the cause of the neurodegenerative disease kuru, has begun a

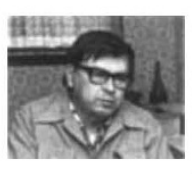
prison sentence of up to one year for sexually abusing at least one of the young boys he brought from New Guinea to his home in the United States.

Colleagues of Gajdusek, who spent his career at the US National Institutes of Health, at first resisted suggestions that he was anything but honorable for his commitment to the care and education of more than 50 young people whom he met in the Pacific islands during his research on kuru. In diaries of his journies, Gajdusek wrote about initiation rites between young boys and adult men, but as allegations mounted he denied sexual encounters with his "adopted children".

However, the truth came to light during a taped telephone call between Gajdusek and his principal accuser, in which the scientist admitted sexual activity but begged the youth to keep quiet. The young man, now grown, refused. "I am an adult and I'm able to reason now that what you did was wrong," he said. Gajdusek, now 73, will be on probation for 14 years when he is released from jail in Frederick County, Maryland.

B.J.C. 